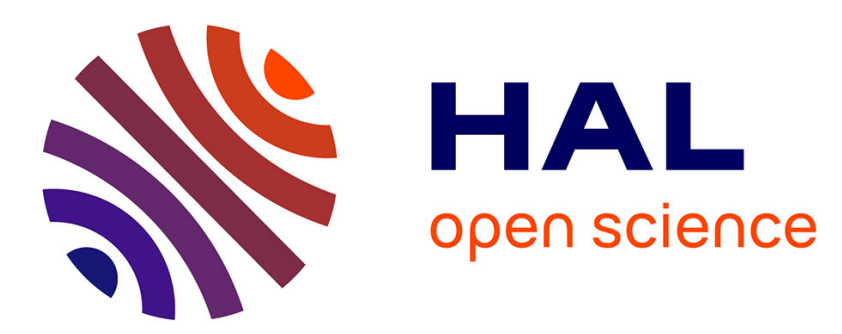

\title{
Investigation of Electrical Latchup and SEL Mechanisms at Low Temperature for Applications down to 50K
}

\author{
A. Al Youssef, L. Artola, S. Ducret, G. Hubert, F. Perrier
}

\section{To cite this version:}

A. Al Youssef, L. Artola, S. Ducret, G. Hubert, F. Perrier. Investigation of Electrical Latchup and SEL Mechanisms at Low Temperature for Applications down to 50K. IEEE Transactions on Nuclear Science, 2017, 64 (8), pp.2089-2097. 10.1109/TNS.2017.2726684 . hal-01629241

\section{HAL Id: hal-01629241 \\ https://hal.science/hal-01629241}

Submitted on 6 Nov 2017

HAL is a multi-disciplinary open access archive for the deposit and dissemination of scientific research documents, whether they are published or not. The documents may come from teaching and research institutions in France or abroad, or from public or private research centers.
L'archive ouverte pluridisciplinaire HAL, est destinée au dépôt et à la diffusion de documents scientifiques de niveau recherche, publiés ou non, émanant des établissements d'enseignement et de recherche français ou étrangers, des laboratoires publics ou privés. 


\title{
Investigation of Electrical Latchup and SEL Mechanisms at Low Temperature for Applications down to $50 \mathrm{~K}$
}

\author{
A. Al Youssef, L. Artola, S. Ducret, G. Hubert, F. Perrier
}

\begin{abstract}
This paper presents a physical investigation of the mechanisms induced by the low temperature on Single-Event Latchup in CMOS inverters for a range of technology nodes (250 $\mathrm{nm}$ from Sofradir and $180 \mathrm{~nm}$ from IBM). For the first time, the TCAD simulations show a good agreement of Latchup characteristics with the experimental measurements at cryogenic temperatures. Additionally, a more robust technology provided by Sofradir was demonstrated.
\end{abstract}

Index Terms - Latchup, Low temperatures mechanisms, TCAD simulations, CMOS technology, Single Event Latchup.

\section{INTRODUCTION}

$\mathrm{S}$ INGLE Event Latchup (SEL) induced by radiation environments in electronics components represent a critical use issue for operational applications. One of the advantages of the use of the CMOS technology for low temperature applications is the decrease in the SEE sensitivity [1] [2]. However, for very low temperature, such as cryogenic applications (below 123K), a decrease in the holding current has been observed experimentally for bulk wafers by Deferm [3]. It means that, a Latchup can occur at cryogenic temperatures due to the triggering of the parasitic pnpn structure. A recent publication of Marshall et al. has revealed the first observation of single particle-induced Latchup (SEL) in CMOS circuitry operated under cryogenic conditions [4]. It should be noted that for reliability concerns, a simple study at high temperature may be not enough to fully characterize the Latchup phenomenon at low temperatures. For the infrared image sensors operating at cryogenic temperatures, in order to reduce the dark current [5], it is critical to consider a large range of low temperatures. The study is performed for a range of temperatures down to $50 \mathrm{~K}$. Recent work [6] started to propose analysis of physical mechanisms which lead to trigger and hold Latchup at cryogenics temperatures.

The literature reveals that the main condition for inducing a Latchup is that the product of the current gain of the inherent bipolar junctions transistors (BJTs) should be higher than 1 [5] [7]. However, as noted in [3] and [4], the ion-induced SEL occurs even if the product of the current gains of the npn and pnp BJTs is lower than 1 for temperatures below

100K. Deferm et al. [3] proposed an extension of the classical

A. Al Youssef, L. Artola, G. Hubert, are with The French Aerospace Lab (ONERA), Toulouse, France (email: ahmad.al youssef@onera.fr Laurent.artola@onera.fr and guillaume.hubert@onera.fr)

A. Al Youssef, S. Ducret, F. Perrier are with infrared detectors company (Sofradir), Grenoble, France (email: samuel.ducret@ sofradir.fr and franck.perrier@sofradir.fr) electrical parasitic BJT gain product expression that introduces the Shallow Level Impact Ionization (SLII) mechanism that can produce an exponential increase in the free carrier density once a threshold electric field is reached in regions of the pnpn structure.

In this paper, the electrical Latchup and SEL sensitivity at low temperature are investigated by Technology Computer Aided Design (TCAD) simulations in order to validate this hypothesis and to analyze the physical mechanisms at state. A peak of holding current at low temperature is observed by TCAD simulations for two technological nodes, i.e., $0.18 \mu \mathrm{m}$ and $0.25 \mu \mathrm{m}$, from IBM and Sofradir technologies respectively. These results are consistent with experimental data. The physical parameters influencing the low temperature Latchup behavior are investigated. Based on a TCAD analysis, the effects of SLII mechanism are thoroughly discussed in section II-C.

For both technologies, several transient TCAD simulations are performed for a wide range of temperatures in order to find the threshold Linear Energy Transfer (LET) required to trigger a SEL, and its correlation with the electrical characteristic parameters $\left(V_{\text {trig }}, I_{\text {trig }}\right.$ and $\left.V_{\text {hold }}, I_{\text {hold }}\right)$.

\section{TCAD SIMULATIONS AT LOW TEMPERATURE}

\section{A. Device structure and simulation setup}

All TCAD simulations have been performed with the Synopsys tools. The pnpn electrical Latchup structure has been built using Sentaurus Structure Editor (Sentaurus Editor) as shown in Fig. 1. The realistic structure is issued from standard $180 \mathrm{~nm}$ source $\mathrm{p}$-MOS/Source n-MOS section and based on complex input process files (doping profiles) of the $7 \mathrm{RF} / \mathrm{SF}$ IBM technology. The cathode width is about $0.6 \mu \mathrm{m}$, the anode width of $0.6 \mu \mathrm{m}$, an anode to cathode spacing (A-C spacing) of $0.44 \mu \mathrm{m}$, anode to $\mathrm{n}$-well contact distance of 0.36 $\mu \mathrm{m}$, and a cathode to substrate contact spacing of $0.36 \mu \mathrm{m}$ [8] [23].

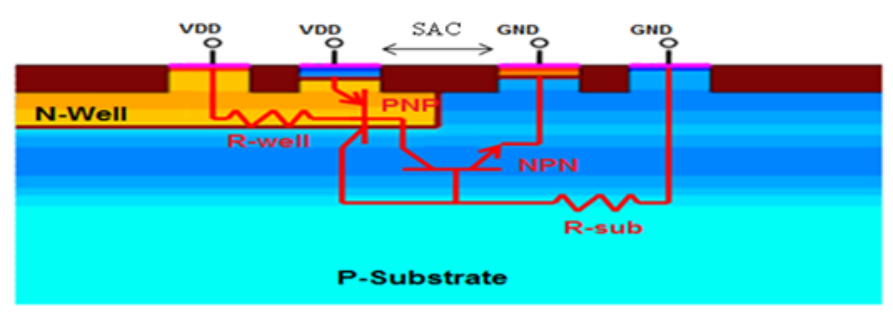

Fig. 1. 2D structure of the Source p-MOS/Source n-MOS section (IBM 7RF/SF) built with Sentaurus Structure Editor [6].

Two carrier transport models have been used for the TCAD simulation: The conventional Drift-Diffusion (DD) 
model and the hydrodynamic (HD) model. Deep-submicron devices cannot be described properly using the conventional drift-diffusion model, especially for a temperature study. The characteristic dimensions of modern devices are well outside the range of validity of the drift-diffusion model. Hence, even though variants of the drift-diffusion equations are still in use for the simulation of recent device generations, their accuracy is highly questionable and leads to poor results already in the linear regime [9]. More accurate macroscopic transport models have been derived based on higher moments of the Boltzmann Transport Equation (BTE). The energy transport model and the hydrodynamic model are derived from the first four moments of the BTE. In the hydrodynamic model, current densities are defined as a function of two main terms; the first term takes into account the contribution due to the spatial variations of electrostatic potential, electron affinity and the band gap. The second term takes into account the contribution due to the gradient of concentration, the carrier temperature gradients and the spatial variation of the effective masses [24]. For this reason, the hydrodynamic model is more complex to be computed than the Drift-diffusion model but it provides a good compromise between physical accuracy and computation time for advanced technologies [9] [24].

In this work, the results of TCAD at low temperature have been obtained with the hydrodynamic laws allowing temperature carriers dependence, Fermi-Dirac statistics, concentration and temperature-dependent mobility, temperature dependent SRH (Shockley-Read-Hall), the Auger recombination, and the band-gap narrowing for high doping region.

In section II.D, hydrodynamic (HD) simulation results (with temperature dependence) are compared with driftdiffusion (DD) simulation results in order to highlight the interest of HD simulations. The impact of incomplete ionization effect at low temperatures is also discussed.

\section{B. Modeling of temperature dependence}

In order to simulate the correct behavior of Latchup phenomenon at cryogenic temperature, the temperature dependence models have been added in TCAD simulation. First of all, Slotboom et al [10] observed that the band gap in n-p-n transistors is narrow for impurity concentrations above $10^{17} \mathrm{~cm}^{-3}$. The band gap narrowing model has been used for all simulated temperatures. When the impurity concentration is high $\left(>10^{19} \mathrm{~cm}^{-3}\right)$, Fermi level will be close to conduction band or valence band. In this case, Fermi (or Fermi-Dirac) statistics become more important than the Boltzmann approximation for high values of carrier densities in the active regions of a silicon device. For low temperature simulations, impurity freeze-out is modeled in TCAD using Fermi-Dirac statistics and degeneracy factors associated with the conduction and valence energy bands [9]. Selberherr et al [11] discussed the modeling of MOS device at $77 \mathrm{~K}$ which requires carrier transport at low temperature (impurity freeze-out), carrier mobility (temperature dependence of scattering mechanisms) and carrier generation-recombination (impact ionization). In TCAD simulation, several carrier mobility models describe the mobility but two carrier mobility models are compatible to simulations at low temperatures: The "Arora" carrier mobility model and the "Philips Unified" mobility model, "PhuMob". Thus, the ionized impurity scattering effect (from SLII occurrence) at low temperature is taken into account in these two mobility models. All TCAD simulations results presented in this paper have been obtained with the "Arora" mobility model which describes the mobility parameter in the global physical simulation model.

It should be noted that all physical assumptions (carriers avalanche, high field saturation, band gap narrowing) required to describe the low-temperature model are used in the simulations.

\section{SLII Mechanisms in freeze-out region}

In this subsection, the modeling of the doping freeze-out at low temperature is discussed. First, as presented in the introduction, the main condition for Latchup occurrence is that the product of gain currents of the inherent bipolar junction transistors (BJTs) exceeds 1 [1] [7].

$$
\beta_{\mathrm{no}} \beta_{\mathrm{po}}>1
$$

Where $\beta_{n o}$ and $\beta_{p o}$ are the common base current gains of the parasitic pnp and npn BJTs. However, as noted in [3] [4], the ion-induced SEL occurs even if the gain product of the common base current gains of the npn and pnp BJTs is below one for temperatures below 150K. Actually, Marshall et al. [4] demonstrated that electrical Latchup can occur under cryogenic temperature in parasitic pnpn structures.

Deferm et al. [3] proposed an extension of the classical electrical parasitic BJT gain product expression that incorporates the Shallow Level Impact Ionization (SLII) mechanism. SLII mechanism can produce an exponential increase in the free carrier density once a threshold electric field is reached in regions of the pnpn structure as defined by equation (2) [3] [4]:

$$
\beta_{\mathrm{no}} \beta_{\mathrm{po}}>\left(\mathrm{M}_{\mathrm{sn}} \mathrm{M}_{\mathrm{sp}}\right)^{-1}
$$

Where $\mathrm{M}_{\mathrm{sn}}$ and $\mathrm{M}_{\mathrm{sp}}$ are the ionization coefficients for the SLII modeling.

At low temperatures, the thermal energy within a semiconductor is not high enough to fully activate all of the donor and acceptor impurity atoms. Then, the carrier concentrations (electron or hole) will not equal the concentrations of doping atoms $\left(\mathrm{N}_{\mathrm{D}}\right.$ or $\left.\mathrm{N}_{\mathrm{A}}\right)$. Fig. 2 (a) shows simulated data of the equilibrium electron concentration as a function of temperature for n-type silicon with a doping concentration of $10^{16} \mathrm{~cm}^{-3}$ [12]. Below $150 \mathrm{~K}$ there is not enough thermal energy within the silicon to fully ionize the impurity atoms. This region of operation is known as the freeze-out regime. Thus, an increase in temperature induces an increase in the percentage of ionized donor impurities. For temperatures between $150 \mathrm{~K}$ and $550 \mathrm{~K}$, there is sufficient thermal energy resides within the silicon to fully ionize the impurities. This region of operation is known as the extrinsic 
regime. The incomplete ionization model at freeze-out regime is taken into account in highly-doped regions $\left(>10^{17} \mathrm{~cm}^{-3}\right)$ [9] [13]. In other regions, incomplete ionization is taken into account in the low-field component of carrier drift mobility [13] [14].

In freeze-out regime, Deferm et al. [3] describes the electrical Latchup process as follow. The pnpn structure in the 'off' state will be in a high resistive state with a reversed biased center pn junction. The structure remains 'off' unless the electric field threshold for Shallow Level Impact Ionization (SLII) is reached. As shown in Fig. 2 (b) the SLII mechanism occurs in freeze-out regime. The free carriers generated from shallow levels dominate the total free carriers issued from the valence band. SLII can occur at low fields (the threshold electric field for SLII corresponds to a voltage drop of $1 \mathrm{~V} \mathrm{[3]}$ [15]). Thus, if there is an external source of free carries that comes from ionizing particle or from electrical stresses and reaches the threshold electric field of SLII, this mechanism will allow the generation of the required energy to ionize an electron from the donor level to the conduction band.

Thus, the SLII mechanism leads to an exponential increase in the current of free carriers. This phenomenon creates even more free carriers in a multiplicative process [3] and leads to a low resistive 'on' state characteristic of the Latchup phenomenon. Fig. 2 (b) also explains the incomplete ionization at freeze-out regime and the complete ionization of doping atoms at the extrinsic and intrinsic regimes as shown in Fig. 2 (a).

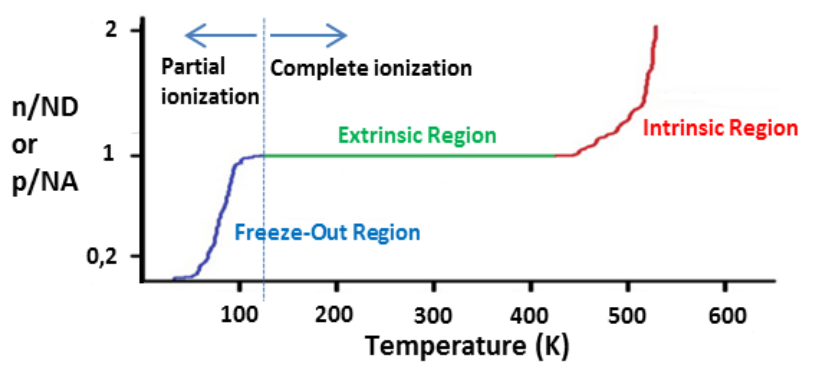

(a)

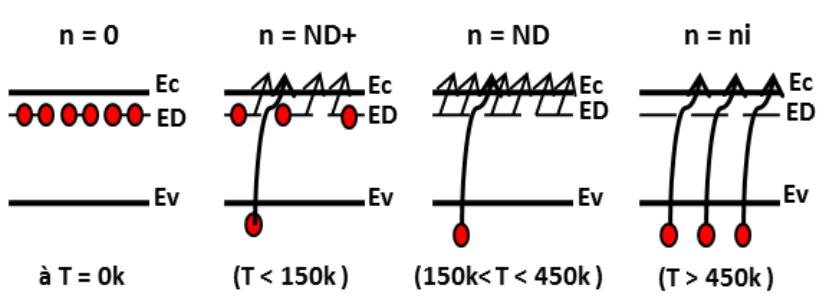

(b)

Fig. 2. (a) Carrier concentration as a function of temperature in n-type silicon showing partial ionization, extrinsic and intrinsic regions [12]. (b) Electron concentration at low (Shallow Level Impact Ionization (SLII)), moderate, high temperature [6].

\section{Temperature dependence of electrical Latchup in IBM technologies}

The electrical stress was performed by TCAD simulations in order to extract the Latchup parameters for the pnpn electrical Latchup structure based on $0.18 \mu \mathrm{m} \quad 7 \mathrm{RF} / \mathrm{SF}$ technology from IBM. The N-well and anode are biased at a typical supply voltage, i.e., $5.0 \mathrm{~V}$, whereas both the cathode and the substrate are grounded. The 2-D structure illustrated in Fig. 1 is the baseline structure used in all of the performed Latchup simulations.

The trigger point $\left(\mathrm{I}_{\text {trig, }}, \mathrm{V}_{\text {trig }}\right)$ and the holding point $\left(\mathrm{I}_{\text {hold, }}\right.$ $\mathrm{V}_{\text {hold }}$ ) are the two main electrical Latchup characteristics (Fig. 3). Latchup immunity condition is obtained when $V_{\text {hold }}>V_{D D}$.

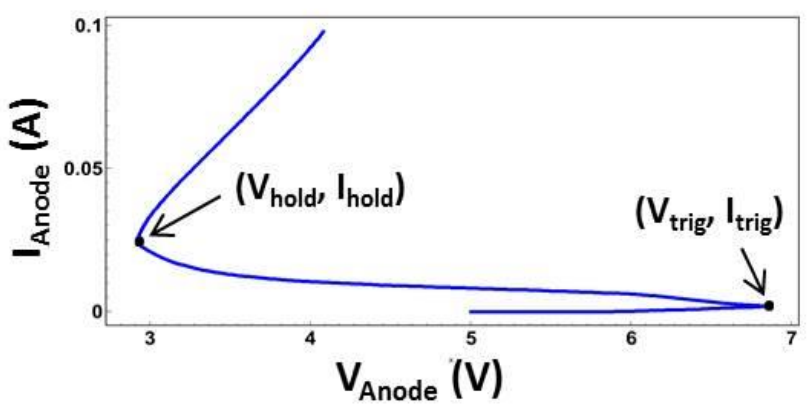

Fig. 3. Typical I-V curve for electrical Latchup characteristics, extracted from static simulation (IBM $180 \mathrm{~nm}$ 7RF/SF) [6].

Fig. 4 shows a comparison between the two types of simulation model: the drift-diffusion model (black diamonds) and the hydrodynamic model (red squares and blue triangles).

The drift-diffusion approach cannot reproduce velocity overshoot and often overestimates the impact ionization generation rates. It is possible to use the drift-diffusion model together with a lattice temperature equation, but it is not mandatory. It is not possible to use the drift-diffusion model for a particular carrier type and to solve the carrier temperature for the same carrier type; the hydrodynamic model is required for that. In this case, the hydrodynamic model provides a good simulation of the physical accuracy as a function of temperature [24].

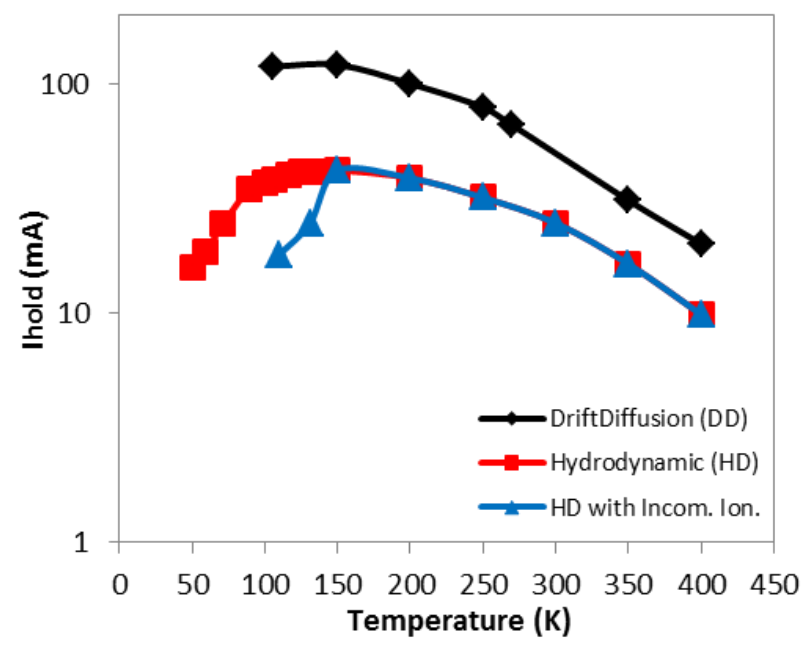

Fig. 4. Holding currents extracted from TCAD simulation as a function of temperature (IBM $180 \mathrm{~nm}$ 7RF/SF) with three type of simulation models: drift-diffusion (black diamonds), hydrodynamic (red squares) and hydrodynamic with incomplete ionization model (blue triangles). Hydrodynamic models provide a good description of SLII phenomenon at low temperature. 
The results obtained by drift-diffusion simulation show a poor description of the SLII phenomenon; A plateau is observed below $150 \mathrm{~K}$. While hydrodynamic model shows current peak which is in good agreement with experimental results [4]. The impact of incomplete ionization is presented by blue triangles curve. Less than $150 \mathrm{~K}$, hydrodynamic simulations with take into account the incomplete ionization model show an important rapid drop of holding current compared with the hydrodynamic model curve (red squares). Then, it is mandatory to use hydrodynamic simulation model in order to well characterize SLII mechanisms at very low temperatures for relevant Latchup estimation [9].

As shown in Fig. 5 and Fig. 7, the holding and trigger parameters have been extracted and plotted as a function of temperatures. Fig. 5 shows the impact of the temperature on the holding current (blue diamonds) and the voltage (red squares) with take into account the hydrodynamic model (HD) at low temperature.

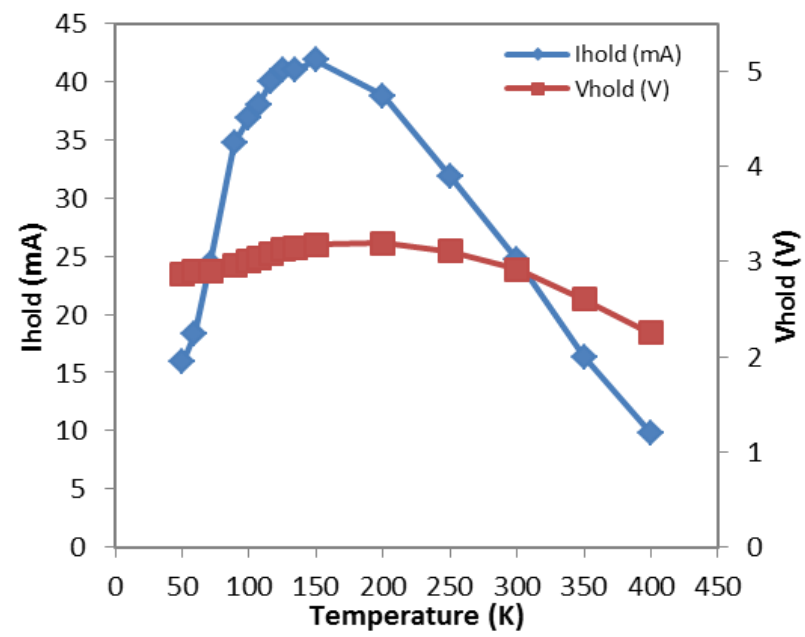

Fig. 5. Holding current and voltage extracted from TCAD simulation as a function of temperature (IBM $180 \mathrm{~nm} 7 \mathrm{RF} / \mathrm{SF}$ ) with take into account the hydrodynamic model. When the temperature is reduced below $150 \mathrm{~K}$, the influence of freeze-out effect becomes important and a decrease in the holding current is observed.

When the temperature is reduced down to $150 \mathrm{~K}$, the holding current and voltage gradually increase. The maximum value, i.e., $3.19 \mathrm{~V}$, of the holding voltage is obtained at about $150 \mathrm{~K}$. At this temperature, very high Latchup immunity is obtained. Below $150 \mathrm{~K}$, the holding current decreases drastically and reaches $15.87 \mathrm{~mA}$ at $50 \mathrm{~K}$. It is interesting to note that this value is nearly the same as the holding current at $320 \mathrm{~K}$. This result seems to indicate a potential similar SEL sensitivity at $50 \mathrm{~K}$ and $320 \mathrm{~K}$. This point will be investigated and discussed in the section IV.

When $\mathrm{V}_{\text {hold }}<\mathrm{V}_{\mathrm{DD}}$, the pnpn structure is said to be latched because it will remain in a high current state until the anode voltage is decreased below a critical level. The holding voltage ( $\mathrm{V}_{\text {hold }}$ ) is a critical parameter since if it is greater than $\mathrm{V}_{\mathrm{DD}}$, Latchup cannot be self-sustained [1]. As shown in Fig. 5, $\mathrm{V}_{\text {hold }}$ is always below $\mathrm{V}_{\mathrm{DD}}$. Notice that the fast drop of the holding current below $150 \mathrm{~K}$ is consistent with SLII onset as observed by Deferm et al. [3].
TCAD simulation results are compared with experimental measurements performed by Marshall et al. [4] and presented in Fig. 6. In this work, electrical measurements have been performed on $130 \mathrm{~nm}$ IBM 8HP CMOS technology in order to explain the high cross section measurements observed at low temperatures. The $130 \mathrm{~nm}$ IBM 8HP device has an A-C spacing of $1.2 \mu \mathrm{m}$ compared to $0.44 \mu \mathrm{m}$ of the $180 \mathrm{~nm}$ IBM 7RF/SF A-C spacing, anode to n-well contact distance of $1 \mu \mathrm{m}$ compared to $0.36 \mu \mathrm{m}$ of the $180 \mathrm{~nm}$ IBM $7 \mathrm{RF} / \mathrm{SF}$ A-C spacing, and a cathode to substrate contact spacing of $0.6 \mu \mathrm{m}$ compared to $0.36 \mu \mathrm{m}$ of the $180 \mathrm{~nm}$ IBM $7 \mathrm{RF} / \mathrm{SF}$ A-C spacing. The holding voltage and current results as a function of temperature range down to $20 \mathrm{~K}$ are shown in Fig. 6. A rapid drop in holding current is observed at cryogenic temperatures. Simulations are in good agreement with experimental results of Marshall et al [4] as shown in Fig. 5 and Fig. 6 respectively.

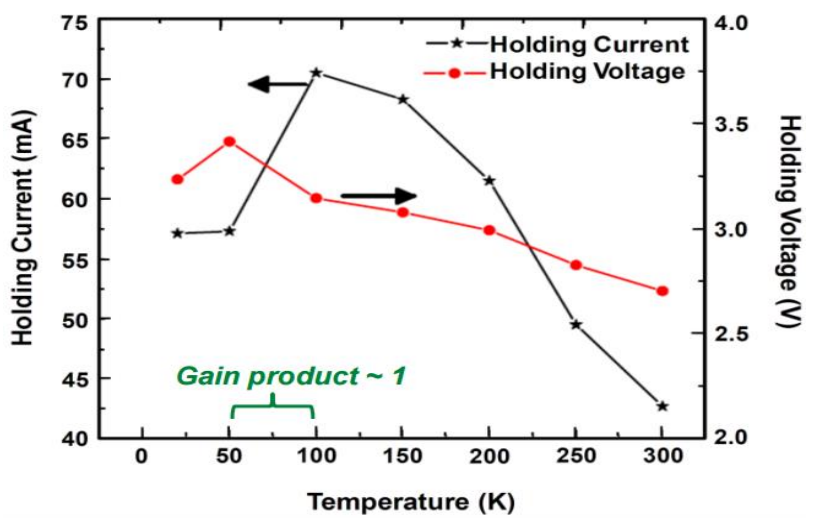

Fig. 6. Experimental electrical LU measurements on a $130 \mathrm{~nm}$ IBM $8 \mathrm{HP}$ CMOS technology of the holding current and voltage as a function of temperature down to $20 \mathrm{~K}[4]$.

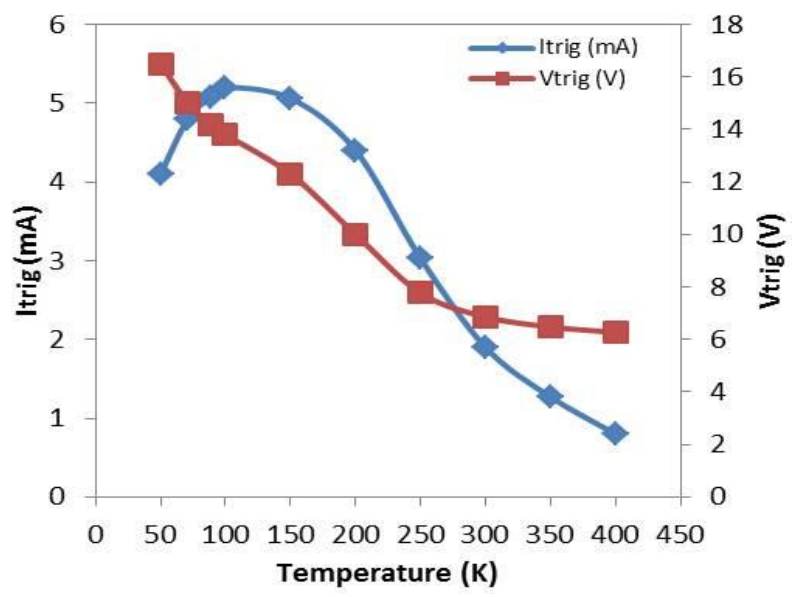

Fig. 7. Trigger current and voltage extracted from TCAD simulation as a function of temperature (IBM $180 \mathrm{~nm} 7 \mathrm{RF} / \mathrm{SF}$ ). When the temperature is reduced, a decrease in the trigger current is observed.

Now, the second characteristic of electrical Latchup ( $I_{\text {trig, }}$, $V_{\text {trig }}$ ) is investigated. When the anode/ $\mathrm{N}$-well junction becomes forward biased, that means the emitter/base junction of pnp transistor becomes forward biased, the pnp transistor turns on, and induces an increase in the anode current. Then, the npn transistor is turned on if there is a potential drop across the substrate resistance which is high enough to. At this point, the 
anode current reaches the trigger point $\left(\mathrm{I}_{\text {trig, }} \mathrm{V}_{\text {trig }}\right)$. Fig. 7 exhibits the impact of the temperature on the trigger current (blue diamonds) and voltage (red squares). When the temperature is reduced down to $100 \mathrm{~K}$ the trigger current is gradually increased. The maximum value, i.e., $5.2 \mathrm{~mA}$ of the trigger current is obtained at $100 \mathrm{~K}$. The trigger voltage is gradually increased when temperature is reduced. The trigger voltage becomes greater than two times the nominal voltage value below 200K. Single-Event can induce a Latchup at low temperature even with this high level of trigger voltage (see next subsection).

\section{E. Physics analysis of electrical Latchup at low temperature in IBM technologies}

An analysis of physical parameters is performed in order to explain the electrical characteristics trends of Latchup as a function of temperature. The physical models used for all the simulations at low temperatures are based on the hydrodynamic laws. Thus, the current densities are defined as a function of carrier density, carrier mobility, electric field, carrier temperature, and others. The current density is proportional to the electrical conductivity $(\sigma)$ and electrical field $(E)$ [16] [17]. The electrical conductivity $(\sigma)$ is calculated by ionized impurity density and carrier mobility as indicated in the following equations:

$$
\begin{aligned}
& \sigma_{n}=q n \mu_{n} \\
& \sigma_{p}=q p \mu_{p} .
\end{aligned}
$$

$q$ : elementary charge, $n$ : electron density, $\mu_{n}$ : electron mobility $p$ : hole density, $\mu_{p}$ : hole mobility.

Thus, the carrier density and the carrier mobility in the active region of vertical pnp and lateral npn bipolar transistors (cf. Fig. 1) are investigated. Fig. 8 (a) and Fig. 8 (b) show the electron and hole densities in pnp transistor base (N-well) and npn transistor base (P-well) respectively as a function of temperature. They are extracted from TCAD simulations when the I-V characteristic reaches the holding point $\left(\mathrm{I}_{\text {hold, }}, \mathrm{V}_{\text {hold }}\right)$ of Latchup. In both cases, a peak of carrier density is obtained at about 150K. Simulations show that the generation of carriers, compared to doping level, at low temperature $(<150 \mathrm{~K})$ is nearly the same as the generation of carriers at high temperatures (>300K). This result indicates the effect of SLII mechanism at low temperature (Fig. 2). The generation of carriers at low temperature will impact the carrier mobility. It is now investigated through using TCAD simulations.

The carrier mobility between the emitter and base of each bipolar transistor are extracted from TCAD simulations and shown in Fig. 9. The electron mobility is extracted in the base of the pnp transistor (in the N-well); while the hole mobility is extracted in the base of the npn transistor (in the substrate) as shown in Fig. 9 (a). Because of the decrease in temperature, the carrier mobility in the emitters and bases of bipolar transistors increases up to $150 \mathrm{~K}$ (in some cases up to $100 \mathrm{~K}$, $200 \mathrm{k}$ ) and decreases down to $50 \mathrm{~K}$. The difference in the temperature value at the peak of the carrier mobility depends on the extraction location. Thus, the characteristics of the switch point of the mobility curve depend on the doping level and especially on the retrograde doping profile in the both regions. It should be note that it's not the first time a decrease of carrier mobility at low temperatures is observed. Li and Thurber [18] have revealed a shift in the trend of mobility when the donor density is greater than $10^{17} \mathrm{~cm}^{-3}$. Apparently, for IBM technology, donor density is greater than $2.10^{17} \mathrm{~cm}^{-3}$ in the regions of the two parasitic bipolar transistors. Another experimental observation was performed by Morin and Maita [19] with $\mathrm{N}_{\mathrm{D}}=1.310^{17} \mathrm{~cm}^{-3}$ and $\mathrm{N}_{\mathrm{A}}=2.210^{15} \mathrm{~cm}^{-3}$, who have

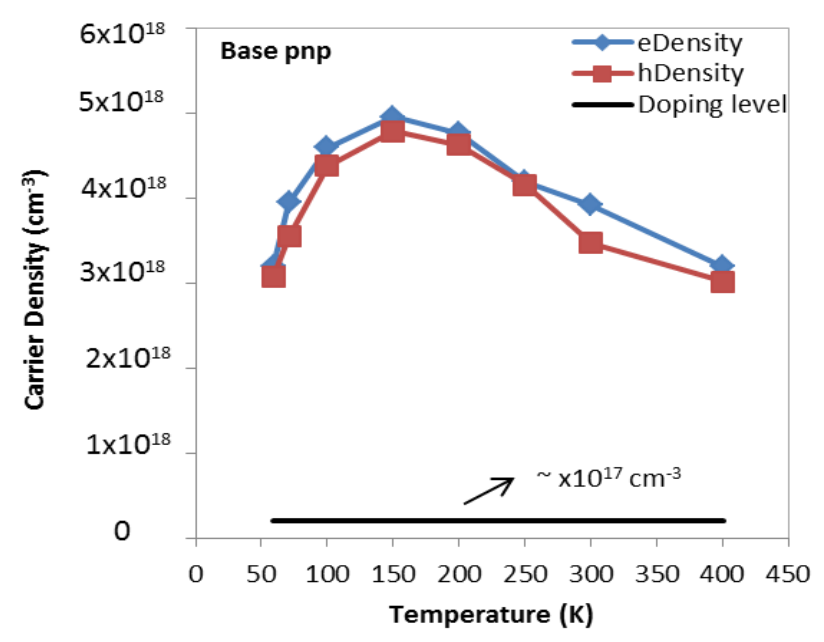

(a)

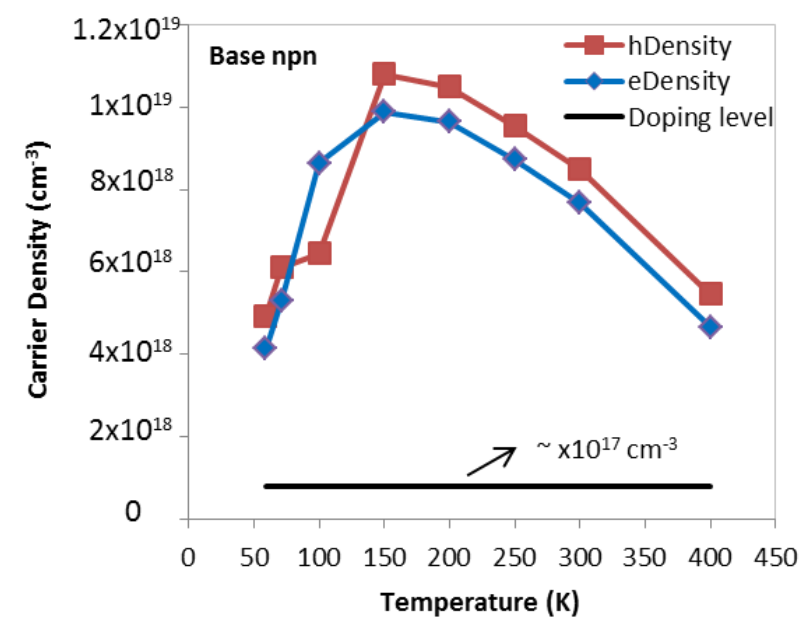

(b)

Fig. 8. Carrier density in the bases regions of bipolar transistors extracted from TCAD simulation as a function of temperature (IBM $180 \mathrm{~nm}$ 7RF/SF (a) Carrier density at base pnp. (b) Carrier density at base npn.

showed a peak of carrier mobility at about $50 \mathrm{~K}$. In fact, carrier mobility is directly proportional to the average relaxation time. And the average relaxation time is directly related to the scattering mechanisms. Then, to calculate the carrier mobility it is necessary to consider the scattering mechanisms in a semiconductor. At low temperatures, ionized impurity scattering is the dominant scattering source for carriers [25]. At low temperatures, electrons move more slowly, and lattice vibrations are small as well (phonon scattering very small); thus, the ion impurity forces which have little impact on highenergy particles become the dominant limit to mobility. In this 
regime, decreasing temperature extends the amount of time electrons spend passing an impurity ion, causing mobility to decrease as temperature decreases, it means that when the mechanism of SLII occurs especially below $150 \mathrm{~K}$. This effect is emphasized in the high dopant concentration $\left(>10^{17} \mathrm{~cm}^{-3}\right)$ [26]. Thus, the carrier mobility peak (Fig. 9) coupled with the carrier density peak (Fig. 8) should explain the rapid drop in the holding current between $50 \mathrm{~K}$ and $150 \mathrm{~K}$ as presented in Fig. 5 and Fig. 6. This is due to the proportionality between current density, carrier density and carrier mobility.

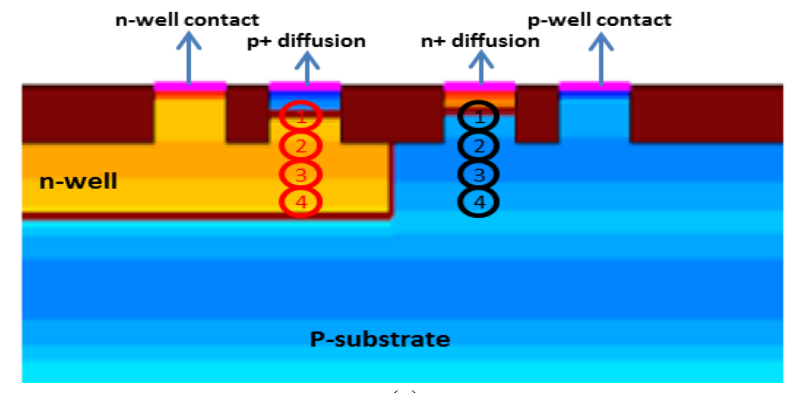

(a)

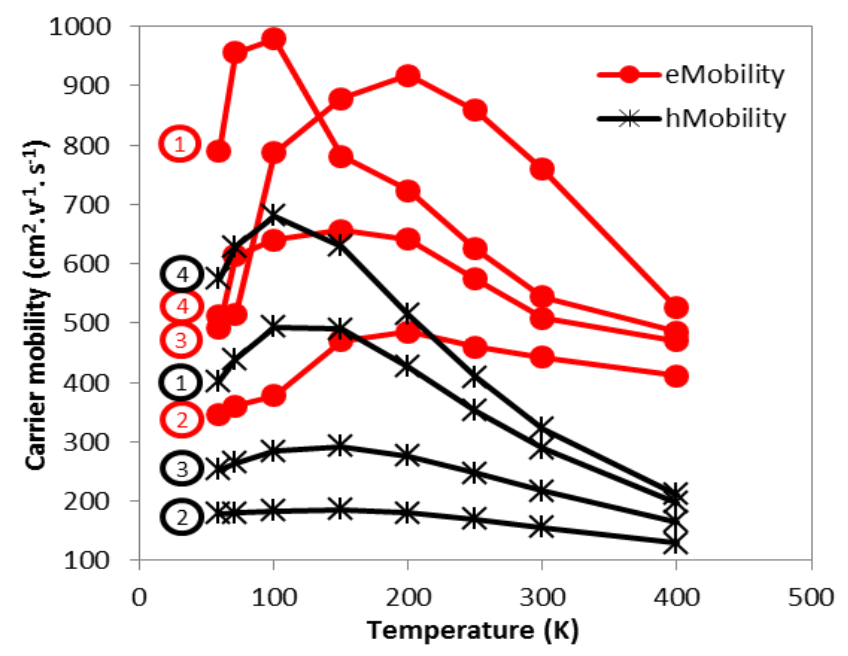

(b)

Fig. 9. (a) 2D structure of the Source p-MOS/Source n-MOS section (IBM 7RF/SF). (b) The electron mobility as a function of depth (red circles) of the emitter and base regions of pnp transistor (red circles) and the hole mobility as a function of depth (black circles) of the emitter and base regions of npn transistor (black star) respectively.

\section{LATCHUP CHARACTERIZATION OF SOFRADIR TECHNOLOGY}

\section{A. Electrical calibration of Sofradir CMOS inverter}

3D TCAD simulations have been realized on a $250 \mathrm{~nm}$ CMOS inverter issued from a D- Flip-Flop of the read-out circuit of infrared detector developed by Sofradir. Its structure has been built using the Sentaurus Structure Editor (Sentaurus Editor). Fig. 10 illustrates a 2-D section of this structure. A deep $\mathrm{P}+$ buried layer located on the whole wafer which was modeled as a Gaussian distribution of boron. Both n-well and p-well regions have been modeled with retrograde doping level as Gaussian distribution of arsenic and boron respectively. The deep $\mathrm{P}+$ buried layer and the p-well retrograde region are used as single-event mitigation techniques [20] [21]. For this reason, the calibration process was made, keeping these two areas with a high doping level. Following the step of creation of the $250 \mathrm{~nm}$ n-MOS and pMOS devices, and after a fine-tuning of the device geometries and doping profiles, the calibration phase has been done.

All Sofradir inverter doping profiles, the $\mathrm{p}+$ diffusion depth, the $\mathrm{n}+$ diffusion depth, the $\mathrm{n}$-well depth and the A-C spacing depth are unknown by the designers. The TCAD calibration steps have been performed by adjusting these doping profiles parameters. The design elements have been obtained from GDS files. The 3D TCAD simulations have been performed for different design and doping profiles parameters in order to converge the TCAD calibrated inverter characteristics to the reference Sofradir inverter characteristics. $V_{\text {out }}$ Vs. $V_{\text {in }}$ characteristics performed by Spice simulation is considered as reference characteristics of Sofradir inverter. Spice simulation and TCAD calibrated simulation are compared and shown in Fig. 11. The relevance of the calibration is highlighted by the good comparison of the $\mathrm{V}_{\text {out }}$ vs. $\mathrm{V}_{\text {in }}$ characteristics. The calibrated structure leads to only 7\% to the Static Noise Margin (SNM) error. This calibrated CMOS structure allows to well be characterized the bipolar parasitic structure for the Latchup analysis of the Sofradir technology. For confidentiality reasons the details of doping profile and design parameters obtained after this calibration are not provided.

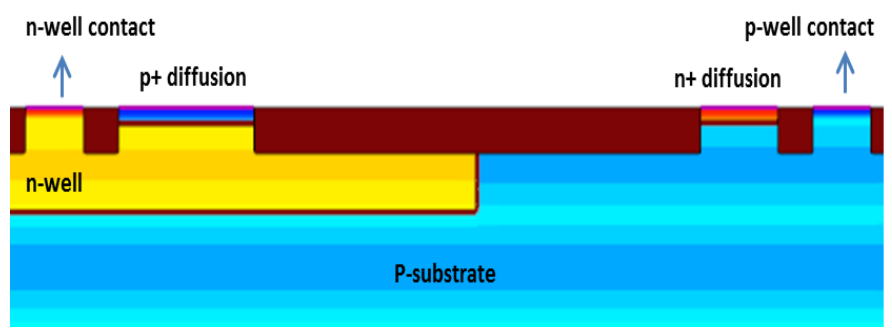

Fig. 10. 2D structure of the Source p-MOS/Source n-MOS section (250 nm Sofradir technology) built with Sentaurus Structure Editor.

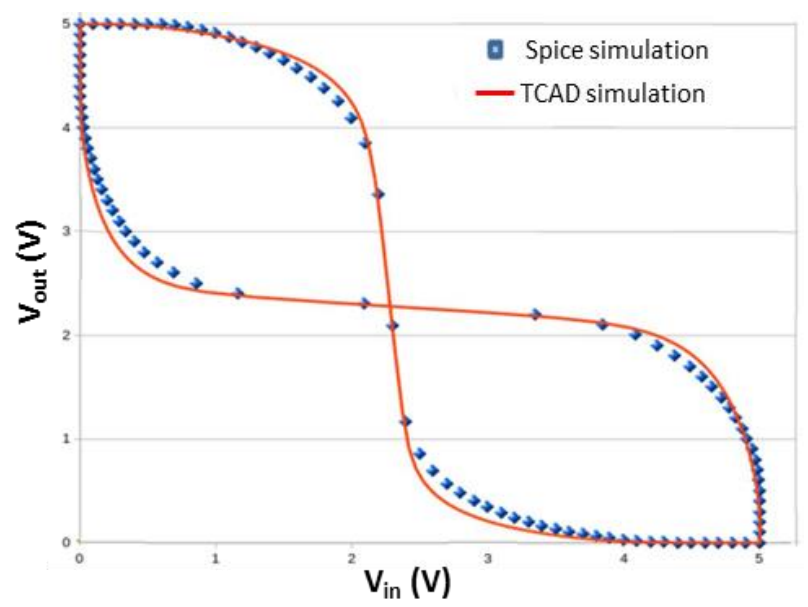

Fig. 11. Comparison of electrical characteristic $\mathrm{V}_{\text {out }}$ versus $\mathrm{V}_{\text {in }}$ of the CMOS inverter obtained by Spice simulation from Sofradir (blue diamonds) and obtained by the calibrated TCAD simulation (red line). 


\section{B. Temperature dependence of electrical Latchup applied to Sofradir technology}

Static simulations have been realized on the calibrated 2-D Sofradir structure presented in section III.A. It would have been better to present that 2-D simulations (Fig. 10) are enough to investigate the Latchup phenomenon in these technologies. The $\mathrm{n}$-well and anode ( $\mathrm{p}+$ diffusion) are biased at a typical supply voltage, i.e., $5.0 \mathrm{~V}$, whereas both the cathode and the substrate are grounded. The holding voltage and current have been extracted and plotted as a function of temperature as shown in Fig. 12. When the temperature is reduced down to $150 \mathrm{~K}$ the holding current $\mathrm{I}_{\text {hold }}$ increases gradually. Below $150 \mathrm{~K}$, the holding current decreases drastically and it reaches $32.11 \mathrm{~mA}$ at $70 \mathrm{~K}$. Compared to previous results (IBM 7RF/SF technology in section II.D), this value is not the same as the holding current at $300 \mathrm{~K}$. Therefore, the Sofradir technology must be less sensitive at cryogenic temperatures than the IBM technology.

In addition, it should be noted that $\mathrm{V}_{\text {hold }}$ is higher than $\mathrm{V}_{\mathrm{DD}}$ when the range of temperature are from $150 \mathrm{~K}$ to $250 \mathrm{~K}$. For temperatures below $150 \mathrm{~K}$ and around $300 \mathrm{~K}$, the holding voltages $\mathrm{V}_{\text {hold }}$ are close to the bias voltage with slight difference $\left(\mathrm{V}_{\text {hold }}-\mathrm{V}_{\mathrm{DD}}=0.14 \mathrm{~V}\right.$ at $70 \mathrm{~K}$, and Vhold- $\mathrm{VDD}=0.34 \mathrm{~V}$ at $300 \mathrm{~K})$. For temperatures which exceed $300 \mathrm{~K}$, the holding voltages decrease down to $3.4 \mathrm{~V}$ at $400 \mathrm{~K}$. It seems that the Sofradir CMOS inverter shows high Latchup immunity for a range of temperatures below $300 \mathrm{~K}$.

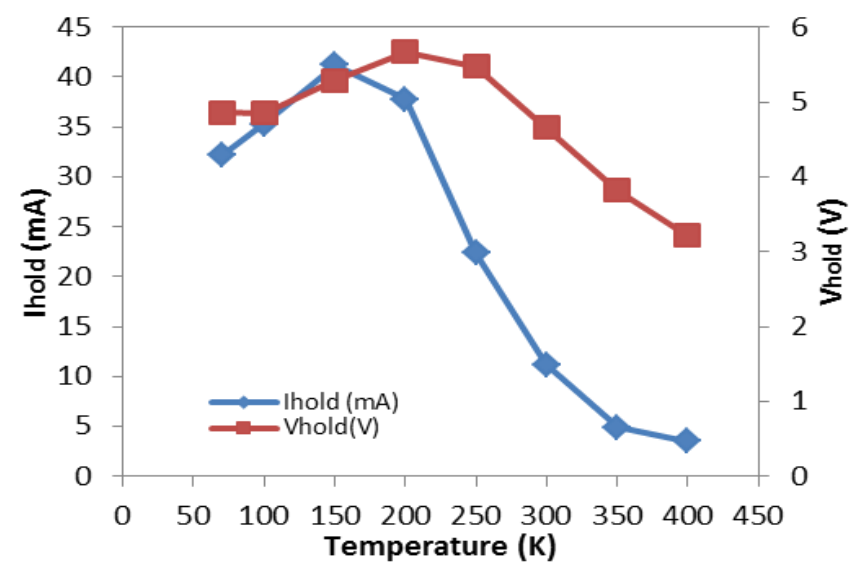

Fig. 12. Holding current and voltage extracted from TCAD simulations as a function of temperature (Sofradir technology $0.25 \mu \mathrm{m}$ ). When the temperature is reduced below $150 \mathrm{~K}$, the influence of freeze-out effects become important and a decrease in the holding current is observed.

Now, the Single-Event Latchup (SEL) is investigated using dynamic TCAD simulations in order to analyze the trend of the threshold Linear Energy Transfer ( $\mathrm{LET}_{\text {th }}$ ) for Latchup occurrence as a function of temperature. LET is the amount of energy lost per unit path length as an ion travels through matter [5], and is typically reported in units of $\mathrm{MeV} \cdot \mathrm{cm}^{2} \cdot \mathrm{mg}^{-1}$.

\section{Single-EVENT LATCHUP INDUCED BY HEAVY ION}

\section{A. Temperature dependence of SEL induced by heavy ions in the IBM technology}

Single-Event Latchup is generated in the 2-D model using the built-in heavy ion function of Synopsys TCAD tools [9]. The heavy ion strike is located in the center of the A-C spacing with a normal incidence. This characterization was performed at 5.0 volts. All other terminals are grounded, as seen in Fig. 1. As shown in Fig. 13, the threshold LET, LET $_{\text {th }}$, has been extracted and plotted as a function of temperature for the IBM $180 \mathrm{~nm}$ technology. The $\mathrm{LET}_{\text {th }}$ gradually increases when the temperature decrease down to $150 \mathrm{~K}$. The maximum $\mathrm{LET}_{\text {th }}$ value, i.e., $78 \mathrm{MeV} . \mathrm{cm}^{2} \cdot \mathrm{mg}^{-1}$ is obtained at $150 \mathrm{~K}$. At this temperature, high Latchup immunity is obtained. Below $150 \mathrm{~K}$, the $\mathrm{LET}_{\text {th }}$ decreases and reaches $62 \mathrm{MeV} . \mathrm{cm}^{2} \cdot \mathrm{mg}^{-1}$ at $100 \mathrm{~K}$. This is in agreement with the explanation of Latchup trigger at low temperature and was investigated in the subsection II-E.

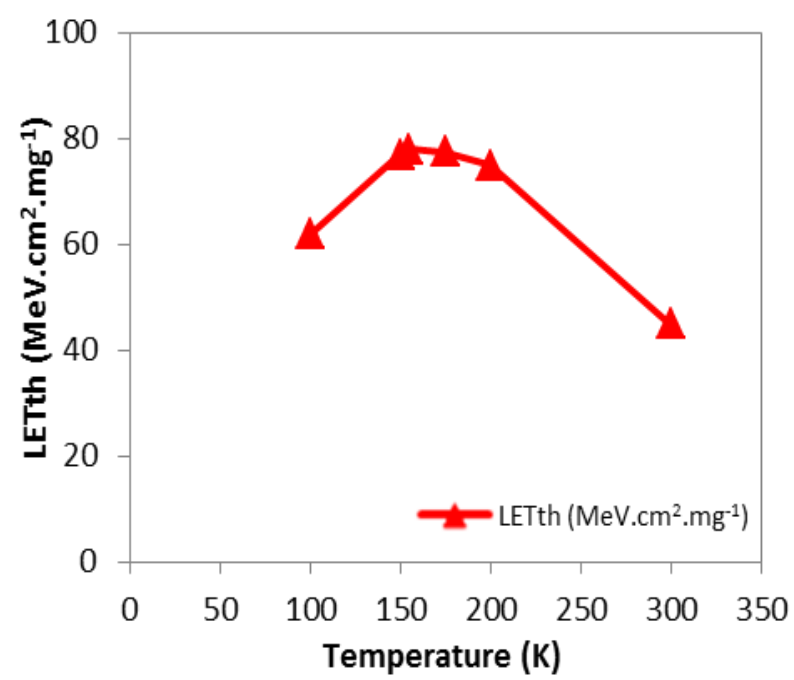

Fig. 13. Threshold LET obtained by TCAD simulations as a function of temperature for the CMOS inverter in IBM $180 \mathrm{~nm}$ 7RF/SF technology [8].

In the next section, the same setup (physical model) of the TCAD simulations is used for the Sofradir technology.

\section{B. Temperature dependence of SEL induced by heavy ions in the Sofradir technology}

Single-Event Latchup is simulated in the 2-D model calibrated in the previous session, using the built-in heavy ion function of Synopsys TCAD tools [9]. The 2-D simulated model correspond to a CMOS structure used in the layout of D- Flip Flop cells tested under heavy ion irradiations at UCL. The heavy-ion strike is located in the center of the A-C spacing at normal incident. This calculation is performed over $\mathrm{N}$-well and anode bias typical supply voltage of 5.0V. All other electrodes are grounded during heavy ion strike.

As shown in Table I, the dynamic simulations have been performed with high LET values 45 and $100 \mathrm{MeV} . \mathrm{cm}^{2} . \mathrm{mg}^{-1}$ at $50 \mathrm{~K}, 70 \mathrm{~K}, 100 \mathrm{~K}, 300 \mathrm{~K}$, and $400 \mathrm{~K}$. At these five values of temperatures, $\mathrm{V}_{\text {hold }}$ is lower than the bias voltage, as shown in Fig. 12. There is no Single-Event Latchup below 300K. Therefore, Sofradir technology is immune to Latchup at low temperature. However, at high temperature, such as 400K, SEL has been observed by TCAD simulation for a LET $=100 \mathrm{MeV} \cdot \mathrm{cm}^{2} \cdot \mathrm{mg}^{-1}$ while it is not the case for a LET $=45 \mathrm{MeV} \cdot \mathrm{cm}^{2} \cdot \mathrm{mg}^{-1}$. This immunity of the Sofradir 
technology has been validated by heavy ion test irradiation at UCL.

SEE test campaign has been performed on D- Flip Flop CMOS device at UCL (Université Catholique de la Neuve) with the heavy ion test facility in Belgium [19]. The CYClotron of Louvain la NEuve (CYCLONE) proposes different heavy ions species which are split in two "Ion cocktails", named M/Q 5 and M/Q 3.3. The heavy ion species were descripted in previous works [22].

During all the test measurements (performed by Sofradir), the temperature of the chip was monitored and regulated, by means of an equipment developed by Sofradir. This cooling equipment allows for regulating the temperature of the DUT to a range of temperature from $77 \mathrm{~K}$ to $300 \mathrm{~K}$. During each irradiation run a GUARD (Graphical Universal Auto Range Delatcher) system has been used on the DUT's power in order to detect SEL and to prevent its destruction [22]. However, no SEL has been measured during the campaign.

Table I: Dynamic TCAD simulations: SEL vs. temperature

\begin{tabular}{|c|c|c|}
\hline $\begin{array}{c}\text { Temperature } \\
(\mathrm{K})\end{array}$ & $\begin{array}{c}\text { LET } \\
\left(\mathrm{MeV} \cdot \mathrm{cm}^{2} \cdot \mathrm{mg}^{-1}\right)\end{array}$ & $\begin{array}{c}\text { Latchup } \\
\text { occurrence }\end{array}$ \\
\hline 50 & 100 & No Latchup \\
\hline 70 & 100 & No Latchup \\
\hline 100 & 100 & No Latchup \\
\hline 300 & 100 & No Latchup \\
\hline \multirow{2}{*}{400} & 45 & No Latchup \\
\cline { 2 - 3 } & 100 & Latchup \\
\hline
\end{tabular}

\section{Design effect of SEL sensitivity of Sofradir technology}

As presented in section IV.B, Sofradir technology is immune to Latchup for a range of temperature up to $300 \mathrm{~K}$. This immunity of the Sofradir technology is due to its specific design and doping profiles. Table II shows the impact of the anode to cathode spacing (A-C spacing) on the SEL sensitivity. The Sofradir doping profiles have been used for the four design configurations. The electrical transient simulations have been done for a heavy ion with a LET of about 50 $\mathrm{MeV} . \mathrm{cm}^{2} . \mathrm{mg}^{-1}$. Four A-C spacing have been simulated: 0.42 $\mu \mathrm{m}, 0.84 \mu \mathrm{m}$ (IBM A-C spacing), $2.4 \mu \mathrm{m}$ and the Sofradir A$\mathrm{C}$ spacing. For confidential reasons the Sofradir A-C spacing is not indicated.

The simulation results show that the Sofradir A-C spacing allows a SEL immunity at $50 \mathrm{MeV} \cdot \mathrm{cm}^{2} \cdot \mathrm{mg}^{-1}$. While thinner A$\mathrm{C}$ spacings induce a SEL sensitivity. Thus, the A-C spacing parameter is an important design element of the SEL device robustness. A complementary study of the impact of design parameters and doping profiles on the SEL hardening will be presented in a future work.

Table II: Dynamic TCAD simulations at $300 \mathrm{~K}$ in Sofradir structure

\begin{tabular}{|c|c|c|}
\hline $\begin{array}{c}\text { Temperature } \\
(\mathrm{K})\end{array}$ & $\begin{array}{c}\text { A-C spacing } \\
(\mu \mathrm{m})\end{array}$ & $\begin{array}{c}\text { Latchup } \\
\text { occurrence }\end{array}$ \\
\hline \multirow{5}{*}{300} & 0,42 & Latchup \\
\cline { 2 - 3 } & $\begin{array}{c}\mathbf{0 , 8 4} \text { (IBM A-C } \\
\text { spacing) }\end{array}$ & Latchup \\
\cline { 2 - 3 } & 2,4 & Latchup \\
\cline { 2 - 3 } & Sofradir A-C \\
spacing & No Latchup \\
\hline
\end{tabular}

\section{DISCUSSION}

Simulations curves illustrated in Fig. 5 and Fig. 13 show Latchup sensitivity at low temperature. As shown in Fig. 5, for the IBM technology, a peak of the holding current is obtained around $150 \mathrm{~K}$, and all the $\mathrm{V}_{\text {hold }}$ values are lower than the bias voltage. Therefore the $180 \mathrm{~nm}$ IBM technology could be sensitive to Latchup whatever the temperature. However, high Latchup immunity is observed at $150 \mathrm{~K}$. This point is confirmed in Fig. 13 with the $\mathrm{LET}_{\mathrm{th}}$ trend.

On the other hand, a peak of holding current is observed in Sofradir technology (Fig. 12), but the holding voltage is often lower than the bias voltage. Actually, from $150 \mathrm{~K}$ to $250 \mathrm{~K}$, $\mathrm{V}_{\text {hold }}$ is higher than $\mathrm{V}_{\mathrm{DD}}$; therefore the Sofradir device exhibits total immunity to Latchup in this temperature range. For temperatures out of this range, $V_{\text {hold }}$ is close to $V_{D D}$ with slight difference $\left(\mathrm{V}_{\text {hold }}-\mathrm{V}_{\mathrm{DD}}=0.12 \mathrm{~V}\right.$ at $\left.100 \mathrm{~K}\right)$, it seems that the CMOS inverter designed with the $250 \mathrm{~nm}$ Sofradir technology shows a high Latchup immunity at low temperature. The lack of Single-Event Latchup shown in Table I confirms this result.

\section{CONCLUSIONS AND PERSPECTIVES}

This work presents the analysis of the mechanisms induced at low temperature on the electrical Latchup and Single-Event Latchup occurrence for two technologies (250nm and 180nm). The Latchup characteristics and the related physical parameters have been investigated for the $250 \mathrm{~nm}$ bulk CMOS technology used by Sofradir in their readout circuit of infrared detectors. The analysis of the Latchup sensitivity at low temperature has been performed by TCAD simulations. A comparison between simulation results and experimental data has been performed at low temperature for the holding current and voltage., the TCAD simulations show a good agreement of Latchup characteristics with the experimental measurements at cryogenic temperatures. This work points out that the SLII mechanisms is the main cause of Latchup occurrence at low temperature.

Therefore, Latchup can occur at cryogenic temperatures for IBM $180 \mathrm{~nm}$ and $130 \mathrm{~nm}$ nodes. The same trends have been presented for the Sofradir technology. However, a stronger robustness of this technology has been demonstrated. Indeed the Sofradir technology shows high Latchup immunity at low 
temperature. As perspective, the technology (doping profile, buried layer, design...) seems to define the corresponding temperature of the maximum value of the holding current peak. The different doping profiles in the substrate are used as single-event mitigation techniques. The impact of doping profiles and design optimizations with the aim to harden the CMOS technology used by Sofradir against Latchup and SEU will be investigated in a future work.

\section{REFERENCES}

[1] J. G. Dooley, and R. C. Jaeger, "Temperature dependence of latchup in CMOS circuits," IEEE Electr. Dev. Lett., vol. 5, no. 2, pp. 41-43, Feb. 1984.

[2] E. Sangiorgi, R. L. Johnston, M. R. Pinto, P. F. Bechtold, and W.Fichtner, "Temperature dependence of latch-up phenomena in scaled CMOS structures," IEEE Electr. Dev. Lett., vol. 7, no. 1, pp. 28-31, Jan. 1986.

[3] L. Deferm, E. Simoen, B. Dierickx, and C. Claeys, "Anomalous latchup behavior of CMOS at liquid helium temperatures," Cryogenics, vol. 30, no. 12, pp. 1051-1055, Dec. 1990.

[4] C. Marshall, P. Marshall, R. Ladbury, A. Waczynski, R. Arora, R. Foltz, J. Cressler, D. Kahle, D. Chen, G. Delo, N. Dodds, J. Pellish, E. Kan, N. Boehm, R. Reed, and K. LaBel, "Mechanisms and Temperature Dependence of Single Event Latchup Observed in a CMOS Readout Integrated Circuit From 16-300 K," IEEE Trans. Nucl. Sci., vol. 57, no. 6, pp. 3078-3086, Dec. 2010.

[5] R. R. Troutman, "Latchup in CMOS Technology," Boston, MA: Kluwer Academic, 1986.

[6] A. Al Youssef, L. Artola, S. Ducret, G. Hubert, and F. Perrier, "Analysis of low temperature on single event latchup mechanisms by TCAD simulations for applications down to 50K," Radecs Proceeding, 2016

[7] S. H. Voldman, "Latchup," West Sussex, U.K.: Wiley, 2007.

[8] IBM, CMOS7RF Design Manuel and Model Guide, Sep. 2007.

[9] C. Jungemann, T. Grasser, B. Neinhüs, and B. Meinerzhagen, "Failure of Moments-Based Transport Models in Nanoscale Devices Near Equilibrium," IEEE Trans. Electr. Dev., vol. 24, no.11, pp. 2404-2408, Nov. 2005.

[10] J.W. Slotboom, "Bandgap Narrowing in Silicon Bipolar Transistors," IEEE Trans. Electr. Dev., vol. 24, no. 8, pp. 1123-1125, Aug. 1977.

[11] S. Selberherr, "MOS Device Modeling at 77 K," IEEE Trans. Electr. Dev., vol. 36, no. 8, pp. 1464-1474, Aug. 1989.

[12] E. Yang, "Microelectronic Devices," New York, McGraw-Hill, 1988.

[13] M. El-Saba, "Transport of Information-Carriers in Semiconductors and Nanodevices," Hershey, PA, Engineering Science Reference, 2017

[14] M. El-Saba, "Yet Another Hydrodynamic Model with Correlated Parameters for Silicon Devices", Microelectronics and Solid State Electronics, vol. 1, no. 5, pp. 118-147, 2012.

[15] E. Simeon, B. Dierickx, L. Deferm, and C. Claeys, "The behavior of silicon p-n junction-based devices at liquid helium temperatures," $J$. Appl. Phys., vol. 70, no. 1016, pp. 1016-1024, 1991.

[16] N. D. Arora, J. R. Hauser, and D. J. Roulston, "Electron and Hole Mobilities in Silicon as a Function of Concentration and Temperature," IEEE Electr. Dev. Lett., vol. ED-29, no. 2, pp. 292-295, Feb. 1982.

[17] Y. Fu, and Z. Li, "Integrated Power Devices and TCAD Simulation," Technology \& Engineering, 2014.

[18] S. Li, and W. Thurber,"The dopant density and temperature dependence of electron mobility and resistivity in n-type silicon," Solid State Electronics, vol. 20, no. 7, pp. 609-616, Jul. 1977.

[19] F. J. Morin, and J. P. Maita, "Electrical properties of silicon Containing Arsenic and Boron," Phys. Rev., vol. 96, no. 1, pp. 28-35, Oct. 1954.

[20] W. Morris, L. Rubin, and D. Wristers, "Buried layer / connecting layer high energy implantation for improved CMOS latch-up," International Conference on Ion Implantation Technology Proceedings, pp. 796799, Jun. 1996.

[21] D.B. Estreich, A. Ochoa, and R.W. Dutton, "An analysis of latch-up prevention in CMOS IC's using an epitaxial-buried layer process", International Electron Devices Meeting, vol. 24, pp. 230-234, Dec. 1978.
[22] L. Artola, G. Hubert, O. Gilard, S. Ducret, F. Perrier, M. Boutillier, P. Garcia, G. Vignon, B. Baradat, and N. Ricard, "Single Event Upset Sensitivity of D-Flip Flop of Infrared Image Sensors for Low Temperature Applications Down to 77 K," IEEE Trans. Nucl. Sci., vol. 62, no. 6, pp. 2979-2987, Dec. 2015.

[23] C. A. Dinkins, "Qualitative characterization of Single Event Transient and Latchup trends in $180 \mathrm{~nm}$ CMOS technology," Master of Science manuscript, Vanderbilt University, May. 2011.

[24] [Online]. Available: https://www.synopsys.com/silicon/tcad.html

[25] D. Wolpert, "Temperature effects in semiconductors in Managing Temperature Effects in Nanoscale Adaptive Systems," chap. 2, pp. 1533, 2000.

[26] W. Grabinski, M. Bucher, JM. Sallese, and F. Krummenacher, "Compact modeling of ultra-deep submicron CMOS devices," International Conference on Signals and Electronic Systems, pp. 1327, 2000. 